\title{
Systematic Review of Fatty Acid Composition of Human Milk from Mothers of Preterm Compared to Full-Term Infants
}

\author{
Szilvia Bokor ${ }^{\mathrm{a}}$ Berthold Koletzko $^{\mathrm{b}}$ Tamás Decsi $^{\mathrm{a}}$ \\ a Department of Paediatrics, University of Pécs, Pécs, Hungary; ${ }^{b}$ Dr. von Hauner Children's Hospital, \\ University of Munich, Munich, Germany
}

\section{Key Words}

Human milk • Essential fatty acid • Full-term infant •

Preterm infant $\cdot$ Long-chain polyunsaturated fatty acid

\begin{abstract}
Background: Fatty acid composition of human milk serves as guidance for the composition of infant formulae. The aim of the study was to systematically review data on the fatty acid composition of human milk of mothers of preterm compared to full-term infants. Methods: An electronic literature search was performed in English (Medline and Medscape) and German (SpringerLink) databases and via the Google utility. Fatty acid compositional data for preterm and fullterm human milk were converted to differences between means and 95\% confidence intervals. Results: We identified five relevant studies publishing direct comparison of fatty acid composition of preterm versus full-term human milk. There were no significant differences between the values of the principal saturated and monounsaturated fatty acids. In three independent studies covering three different time points of lactation, however, docosahexaenoic acid (DHA) values were significantly higher in milk of mothers of preterm as compared to those of full-term infants, with an extent of difference considered nutritionally relevant. Conclusion: Higher DHA values in preterm than in full-term human milk underlines the importance of using own mother's milk
\end{abstract}

for feeding preterm babies and raises the question whether DHA contents in preterm formulae should be higher than in formulae for full-term infants. Copyright $\odot 2008$ S. Karger AG, Basel

\section{Introduction}

The availability of long-chain polyunsaturated fatty acids (LCPUFAs) and especially the supply of docosahexaenoic acid (DHA) appears to modify the development of visual and cognitive functions during early life [1-5]. The LCPUFA content of the diet influences membrane structure and function, and also effects the production of second messengers, such as eicosanoids that influence many cell-associated functions [6]. During gestation and infancy, the supply of preformed LCPUFA can influence neural functions [6]. LCPUFAs accumulate in the fetal tissues primarily during the period of rapid growth in the last trimester of pregnancy $[7,8]$, a period of fetal adipose tissue development [9] and extensive brain growth [10]. Essential fatty acids cannot be synthesized by humans and must be supplied through placental transport to the fetus and with human milk or milk substitute formulae to the infant. Human milk supplies not only the essential fatty acids linoleic and $\alpha$-linolenic acids, but also their LCPUFA metabolites $[1,19]$. Lipid con-

\section{KARGER \\ Fax +4161306 1234 E-Mail karger@karger.ch} www.karger.com
(C) 2008 S. Karger AG, Basel

0250-6807/07/0516-0550\$23.50/0

Accessible online at:

www.karger.com/anm
Dr. Tamás Decsi

Department of Paediatrics, University of Pécs

Pécs, József A. u. 7.

HU-7623 Pécs (Hungary)

Tel. +36 72535 900, Fax +36 72535 971, E-Mail tamas.decsi@aok.pte.hu 
tent and fatty acid composition of human milk is reportedly influenced by a variety of variables such as genetic background of the lactating woman, maternal nutritional status, maternal dietary intakes immediately before and during gestation, the number of previously breastfed infants and the stage of lactation $[1,8,9]$. It has also been debated whether fatty acid composition of human milk differs after preterm as compared to full-term delivery [13-17]. This question is of relevance for determining optimal dietary fatty acid intake of pregnant and lactating woman as well as LCPUFA contents of formulae for preterm infants.

This paper systematically reviews the published information on fatty acid composition of human milk in mothers of preterm as compared to those of full-term infants.

\section{Methods}

We performed an electronic literature search in English (Medline (www.pubmed.com) and Medscape (www.medscape.com)) and German (SpringerLink (www.springerlink.com)) databases from their start dates to November 2005 onwards. The searching expressions were as follows: human milk or breast milk, combined with essential fatty acid or long-chain polyunsaturated fatty acid or arachidonic acid or docosahexanoic acid. We also checked the list of references in the publications identified. We attempted to reveal unpublished evidence by consulting abstract books of relevant scientific meetings and by contacting experts working in this field.

Fatty acid composition of preterm or full-term human milk was reported in several studies, whereas data obtained in direct comparison of the fatty acid composition of preterm and fullterm human milk within the same study were published only in five reports. Each of these studies was a longitudinal study and investigated human milk from apparently healthy mothers who had delivered preterm or full-term infants. Both pregnancies and deliveries were normal in all these studies. The gestational ages of preterm infants were between 25 and 36 weeks, whereas those of full-term infants were $>37$ weeks. There was no history of any disease of the offspring. All the women in the study of GenzelBoroviczény et al. [15], Luukkainen et al. [14] and Kovács et al. [17] were apparently on omnivorous diet. No information was given about the dietary background of mothers in the study of Bitman et al. [13] and Rueda et al. [16].

There were some methodological differences in the studies reviewed here. The sample collections were at different time points of lactation (for details see Results). Storage temperature of the milk samples was either -20 or -70 or $-80^{\circ} \mathrm{C}$. For fatty acid analysis, lipids were extracted either with chloroform-methanol or using a mixture of benzene-methanol-acetylchloride. Fatty acid methyl esters were determined by capillary gas liquid chromatography in all studies except the classical study of Bitman et al. [13], who used packed column gas liquid chromatography being the predominant method at the time. Results of the fatty acid composition were expressed as weight percentages of all fatty acids and were presented as means and SD [16], means and SE [13], median and IQR $[15,17]$ or means and 95\% confidence intervals (CIs) [14]. For a better comparability, we calculated all data into the form of means and SD from the published data or the original databases of the two studies where medians and interquartile ranges were published $[15,17]$. For arachidonic acid (AA) and docosahexanoic acid (DHA) values, i.e. the principal LCPUFAs of human milk we also calculated the difference of means between preterm and full-term milk and the $95 \%$ CIs of the difference of means by using the following formulae:

$$
\begin{aligned}
& \mathrm{PSD}=\sqrt{\left[\left(N_{1}-1\right) s_{1 x} s_{1}+\left(N_{2}-1\right) s_{2 x} s_{2} /\left(N_{1}+N_{2}-2\right)\right]} \\
& \mathrm{SED}=\mathrm{PSD} \times \sqrt{\left[\left(1 / N_{1}\right)+\left(1 / N_{2}\right)\right]} \\
& 95 \% \mathrm{CI}=\left(\mathrm{X}_{1}-\mathrm{X}_{2}\right) \pm \mathrm{t}^{*} \times \mathrm{SED}
\end{aligned}
$$

where PSD = pooled SD, $\mathrm{N}_{1}=$ number of subjects in group 1 (in our study: preterm), $\mathrm{s}_{1}=$ standard deviation of group $1, \mathrm{~N}_{2}=$ number of subjects in group 2 (in our study: full-term), $s_{2}=$ standard deviation of group 2; SED = standard error of the difference, $X_{1}=$ mean of group $1, \mathrm{X}_{2}=$ mean of group $2, \mathrm{t}^{*}=$ value of $\mathrm{t}$-distribution at the given confidence level with degree of freedom $=\mathrm{N}_{1}+$ $\mathrm{N}_{2}-2$.

\section{Results}

Fatty acid compositions of preterm and full-term human milk investigated in 18 comparisons published in five studies are shown in tables 1-3.

Preterm breast milk showed higher contents of the saturated fatty acids myristic acid (C14:0) at two different time points in the study of Kovács et al. [17] and in the study of Genzel-Boroviczény et al. [15], palmitic acid (C16:0) values at one time point in the study of Kovács et al. [17] and stearic acid (C18:0) values at one time point in the study of Luukkainen et al. [14] (table 1). The cismonounsaturated fatty acid oleic acid (C18:1n-9) was higher in preterm milk at two different time points in the study of Kovács et al. [17] and at three different times in the study of Rueda et al. [16] (table 1). Values of the principal $n-6$ polyunsaturated fatty acids, linoleic acid (C18: 2n-6, LA), $\gamma$-linolenic acid (C18:3n-6, GLA) and arachidonic acid (C20:4n-6, AA) values were reported in all studies, whereas dihomo- $\gamma$-linolenic acid (C20:3n-6, DHGLA) values were reported only in four studies. Data on the principal $\mathrm{n}-3$ polyunsaturated fatty acids, docosapentaenoic acid (C22:5n-3) and docosahexaenoic acid (C22:6n-3, DHA) were reported in all studies, whereas eicosapentaenoic acid (C20:5n-3, EPA) values were reported only in four and $\alpha$-linolenic acid (C18:3n-3, ALA) values in three studies. 
Table 1. Major saturated and cis-monounsaturated fatty acids in preterm and full-term human milk

\begin{tabular}{|c|c|c|c|c|c|c|c|c|c|c|}
\hline \multirow[t]{2}{*}{$\begin{array}{l}\text { Day of } \\
\text { lactation }\end{array}$} & \multicolumn{2}{|c|}{$\begin{array}{l}\text { Number } \\
\text { of samples }\end{array}$} & \multicolumn{2}{|l|}{ C14:0 } & \multicolumn{2}{|l|}{$\mathrm{C} 16: 0$} & \multicolumn{2}{|l|}{ C18:0 } & \multicolumn{2}{|l|}{ C18:1n-9 } \\
\hline & $\begin{array}{l}\text { pre- } \\
\text { term }\end{array}$ & $\begin{array}{l}\text { full- } \\
\text { term }\end{array}$ & preterm & full-term & preterm & full-term & preterm & full-term & preterm & full-term \\
\hline \multicolumn{11}{|c|}{ Bitman et al. [13] (USA) } \\
\hline $42(\mathrm{VPT})$ & 18 & 6 & $8.41(3.32)$ & $5.68(3.31)$ & $20.13(5.6)$ & $22.2(5.58)$ & $7.24(4.52)$ & $7.68(4.53)$ & $33.41(6.69)$ & $35.51(6.69)$ \\
\hline $42(\mathrm{PT})$ & 28 & 6 & $7.55(4.71)$ & $5.68(3.31)$ & $23.16(7.59)$ & $22.2(5.58)$ & $7.25(6.17)$ & $7.68(4.53)$ & $33.74(9.13)$ & $35.51(6.69)$ \\
\hline \multicolumn{11}{|c|}{ Luukkainen et al. [14] (Finland) } \\
\hline $1-7$ & 12 & 8 & $7.47(5.10)$ & $6.64(4.67)$ & $28.27(4.70)$ & $29.04(3.63)$ & $9.8(1.47)$ & $9.95(3.16)$ & $39.17(6.85)$ & $38.92(6.88)$ \\
\hline $8-14$ & 11 & 10 & $9.88(6.14)$ & $8.12(5.12)$ & $27.89(2.20)$ & $28.39(5.37)$ & $9.62(1.35)^{* *}$ & $11.38(2.16)$ & $37.65(4.45)$ & $38.00(5.88)$ \\
\hline $15-21$ & 9 & 7 & $7.96(4.11)$ & $6.36(6.65)$ & $26.00(4.36)$ & $27.66(6.88)$ & $9.48(2.47)$ & $10.43(2.55)$ & $38.83(4.45)$ & $39.71(7.47)$ \\
\hline $22-27$ & 16 & 10 & $8.77(3.40)$ & $7.86(5.77)$ & $26.20(3.25)$ & $27.53(5.08)$ & $10.29(1.61)$ & $10.82(3.31)$ & $38.47(2.42)$ & $38.03(7.33)$ \\
\hline $28-35$ & 14 & 5 & $7.7(2.57)$ & $8.7(5.85)$ & $26.12(4.26)$ & $28.02(7.35)$ & $10.27(1.66)$ & $10.00(7.43)$ & $38.61(2.64)$ & $36.95(6.49)$ \\
\hline \multicolumn{11}{|c|}{ Genzel-Boroviczény et al. [15] (Germany) } \\
\hline 5 & 19 & 32 & $7.65(1.64)$ & $6.93(2.49)$ & $23.84(3.16)$ & $24.56(5.14)$ & $6.66(0.92)$ & $7.23(1.10)$ & $33.49(6.67)$ & $32.16(4.22)$ \\
\hline 10 & 19 & 38 & $8.7(2.26)^{*}$ & $7.07(2.5)$ & $22.74(3.02)$ & $22.29(6.25)$ & $7.61(1.48)$ & $7.60(1.22)$ & $29.73(9.58)$ & $31.59(4.26)$ \\
\hline 20 & 17 & 38 & $9.15(2.73)^{*}$ & $7.29(1.81)$ & $22.42(1.88)$ & $23.16(3.07)$ & $8.03(1.50)$ & $7.69(1.21)$ & $31.18(3.95)$ & $31.74(3.04)$ \\
\hline 30 & 13 & 38 & $8.98(3.08)$ & $7.39(2.51)$ & $22.74(2.64)$ & $22.76(1.62)$ & $7.73(1.22)$ & $7.47(1.22)$ & $31.52(4.28)$ & $30.74(5.81)$ \\
\hline \multicolumn{11}{|c|}{ Rueda et al. [16] (Spain) } \\
\hline $1-5$ & 6 & 16 & $6.70(2.17)$ & $6.60(1.79)$ & $21.05(0.79)$ & $20.81(2.19)$ & $5.69(0.53)$ & $7.36(4.13)$ & $30.70(3.49)^{*}$ & $34.93(2.67)$ \\
\hline $6-15$ & 6 & 16 & $7.57(2.04)$ & $8.21(2.25)$ & $19.56(2.19)$ & $19.59(2.19)$ & $6.09(1.05)$ & $6.28(1.01)$ & $39.86(5.47)^{* *}$ & $33.61(3.26)$ \\
\hline $16-35$ & 6 & 16 & $6.27(1.60)$ & $6.42(3.00)$ & $19.03(4.68)$ & $18.85(2.57)$ & $6.50(1.97)$ & $6.70(0.89)$ & $38.14(5.25)^{*}$ & $47.37(6.42)$ \\
\hline \multicolumn{11}{|c|}{ Kovács et al. [17] (Hungary) } \\
\hline 1 & 8 & 10 & $6.18(2.25)$ & $5.19(1.51)$ & $24.21(3.05)^{*}$ & $27.78(2.21)$ & $4.99(1.17)$ & $5.33(0.99)$ & $35.82(4.42)$ & $35.73(3.18)$ \\
\hline 4 & 8 & 10 & $9.36(5.13)$ & $6.10(1.66)$ & $23.97(2.46)$ & $25.47(2.72)$ & $4.97(0.85)$ & $5.29(1.33)$ & $33.24(5.47)$ & $36.02(2.14)$ \\
\hline 7 & 8 & 10 & $9.68(4.64)^{* * *}$ & $5.69(1.63)$ & $23.02(2.46)$ & $25.16(3.25)$ & $5.35(1.01)$ & $5.44(1.07)$ & $32.3(4.25)$ & $36.37(2.8)$ \\
\hline 14 & 8 & 10 & $9.87(4.59)^{*}$ & $5.55(1.82)$ & $22.83(3.38)$ & $23.49(1.69)$ & $5.42(0.43)$ & $5.32(0.93)$ & $32.38(3.92)^{* *}$ & $35.94(2.54)$ \\
\hline 21 & 8 & 10 & $8.36(2.69)$ & $5.68(2.34)$ & $22.41(4.87)$ & $23.78(3.38)$ & $5.41(0.57)$ & $5.78(1.45)$ & $31.21(2.84)^{*}$ & $36.01(4.24)$ \\
\hline
\end{tabular}

$\mathrm{VPT}=$ Very preterm, $\mathrm{PT}=$ preterm.

Data are in weight percent presented as means $(\mathrm{SD}) .{ }^{*} \mathrm{p}<0.05,{ }^{* *} \mathrm{p}<0.001$.

Values of LA, ALA and EPA did not differ between preterm and full-term human milk in any of the five studies. In contrast, GLA values were significantly higher in colostrum of mothers giving birth to preterm infants than in those delivering at term in the study of Kovács et al. [17]. Values of the principal n-3 LCPUFA DHA were significantly higher in preterm breast milk at 1, 4, 7, 14 and 21 days, and of the n-6 LCPUFA AA at all time points except day 14 in the study of Kovács et al. [17], whereas both fatty acids were found at higher levels only at days $28-35$ by Luukkainen et al. [14] (tables 2, 3). Values of the major intermediary metabolite of the synthesis of AA, DHGLA, were found to be significantly higher in milk samples obtained from mothers of preterm than in those collected from mothers of full-term infants in the study of Kovács et al. [17], and values of C22:5n-3 (intermediary metabolite of the synthesis of
DHA) were significantly higher in preterm breast milk in the study of Kovács et al. [17] at 7 and 21 days, and in the study of Luukkainen et al. [14] at 12 and 26 weeks (table 2, 3).

The differences of the means and the 95\% CIs of the difference for DHA and AA values measured in milk samples obtained from mothers of preterm and full-term infants in the five studies are shown in figures 1 and 2, respectively. The difference of mean DHA values (preterm vs. term) were significantly different from zero in three studies [14, 16, 17], covering three different time points. In the study of Kovács et al. [17], AA value difference were positive at three different time points of lactation, whereas the data of Rueda et al. [16] showed negative 95\% CIs for AA values at two different time points of lactation. 
Table 2. Major n-3 polyunsaturated fatty acids in preterm and full-term human milk

\begin{tabular}{|c|c|c|c|c|c|c|c|c|}
\hline \multirow{2}{*}{$\begin{array}{l}\text { Day of } \\
\text { lactation }\end{array}$} & \multicolumn{2}{|l|}{$C 18: 3 n-3$} & \multicolumn{2}{|l|}{$C 20: 5 n-3$} & \multicolumn{2}{|l|}{$C 22: 5 n-3$} & \multicolumn{2}{|c|}{$\mathrm{C} 22: 6 n-3$ (DHA) } \\
\hline & preterm & full-term & preterm & full-term & preterm & full-term & preterm & full-term \\
\hline \multicolumn{9}{|c|}{ Bitman et al. [13] } \\
\hline $42(\mathrm{VPT})$ & $0.76(0.52)$ & $1.03(0.51)$ & $0.55(0.72)$ & n.d. & $0.42(0.36)$ & $0.11(0.36)$ & $0.24(0.36)$ & $0.23(0.34)$ \\
\hline $42(\mathrm{PT})$ & $0.76(0.71)$ & $1.03(0.51)$ & n.d. & n.d. & $0.12(0.51)$ & $0.11(0.36)$ & $0.21(0.46)$ & $0.23(0.34)$ \\
\hline \multicolumn{9}{|c|}{ Luukkainen et al. [14] } \\
\hline $1-7$ & $0.85(0.34)$ & $1.01(0.27)$ & $0.1(0.05)$ & $0.08(0.04)$ & $0.32(0.78)$ & $0.24(0.49)$ & $0.54(1.32)$ & $0.44(0.89)$ \\
\hline $8-14$ & $1.01(0.66)$ & $1.06(0.67)$ & $0.09(0.15)$ & $0.08(0.08)$ & $0.22(0.54)$ & $0.16(0.33)$ & $0.42(1.03)$ & $0.38(0.77)$ \\
\hline $15-21$ & $1.33(1.05)$ & $1.22(0.78)$ & $0.08(0.07)$ & $0.09(0.08)$ & $0.19(0.46)$ & $0.24(0.49)$ & $0.3(0.73)$ & $0.3(0.61)$ \\
\hline $22-27$ & $1.21(0.49)$ & $1.3(0.49)$ & $0.11(0.09)$ & $0.1(0.08)$ & $0.21(0.51)^{* *}$ & $0.1(0.20)$ & $0.35(0.86)$ & $0.18(0.37)$ \\
\hline $28-35$ & $1.24(0.44)$ & $1.45(1.16)$ & $0.09(0.02)$ & $0.07(0.1)$ & $0.22(0.53)^{* *}$ & $0.08(0.16)$ & $0.39(0.95)^{* *}$ & $0.18(0.37)$ \\
\hline \multicolumn{9}{|c|}{ Genzel-Boroviczény et al. [15] } \\
\hline 5 & $0.73(0.49)$ & $0.66(0.19)$ & $0.04(0.06)$ & $0.11(0.21)$ & $0.23(0.05)$ & $0.22(0.08)$ & $0.45(0.11)$ & $0.45(0.11)$ \\
\hline 10 & $0.74(0.26)$ & $0.84(0.27)$ & $0.04(0.06)$ & $0.03(0.08)$ & $0.17(0.04)$ & $0.17(0.05)$ & $0.37(0.14)$ & $0.39(0.09)$ \\
\hline 20 & $0.78(0.21)$ & $0.82(0.27)$ & $0.08(0.15)$ & $0.06(0.09)$ & $0.17(0.11)$ & $0.17(0.05)$ & $0.29(0.26)$ & $0.30(0.13)$ \\
\hline 30 & $0.96(0.38)$ & $0.74(0.17)$ & $0.05(0.07)$ & $0.12(0.18)$ & $0.15(0.06)$ & $0.17(0.08)$ & $0.25(0.05)$ & $0.32(0.25)$ \\
\hline \multicolumn{9}{|c|}{ Rueda et al. [16] } \\
\hline $1-5$ & n.d. & n.d. & $0.15(0.04)$ & $0.20(0.19)$ & $0.42(0.2)$ & $0.4(0.2)$ & $0.48(0.11)$ & $0.86(0.96)$ \\
\hline $6-15$ & n.d. & n.d. & $0.19(0.01)$ & $0.10(0.05)$ & $0.31(0.07)$ & $0.26(0.29)$ & $0.48(0.2)$ & $0.41(0.12)$ \\
\hline $16-35$ & n.d. & n.d. & n.d. & $0.07(0.03)$ & n.d. & $0.17(0.04)$ & $0.69(0.42)$ & $0.33(0.12)$ \\
\hline \multicolumn{9}{|c|}{ Kovács et al. [17] } \\
\hline 1 & $0.42(0.27)$ & $0.28(0.14)$ & n.d. & n.d. & $0.19(0.11)$ & $0.10(0.09)$ & $0.32(0.12)^{*}$ & $0.25(0.14)$ \\
\hline 4 & $0.39(0.20)$ & $0.34(0.23)$ & n.d. & n.d. & $0.14(0.05)$ & $0.08(0.07)$ & $0.30(0.13)^{*}$ & $0.20(0.11)$ \\
\hline 7 & $0.49(0.21)$ & $0.41(0.25)$ & n.d. & n.d. & $0.12(0.05)^{*}$ & $0.06(0.05)$ & $0.32(0.13)^{* *}$ & $0.16(0.09)$ \\
\hline 14 & $0.49(0.25)$ & $0.43(0.19)$ & n.d. & n.d. & $0.11(0.06)$ & $0.05(0.03)$ & $0.24(0.12)^{*}$ & $0.15(0.09)$ \\
\hline 21 & $0.46(0.20)$ & $0.39(0.14)$ & n.d. & n.d. & $0.12(0.07)^{*}$ & $0.05(0.03)$ & $0.19(0.07)^{*}$ & $0.13(0.07)$ \\
\hline
\end{tabular}

$\mathrm{VPT}=$ Very preterm, PT = preterm; n.d. = not determined.

Data are in weight percent presented as means (SD). ${ }^{*} \mathrm{p}<0.05,{ }^{* *} \mathrm{p}<0.001$.

Fig. 1. The differences of the means and the $95 \%$ CIs of the difference for arachidonic acid values measured in milk samples obtained from mothers of preterm and full-term infants in five studies. Each horizontal line represents one statistical comparison. The middle symbol on the horizontal line depicts mean value, whereas the lateral symbols show 95\% CIs. $\downarrow=$ Bitman et al. [13]: preterm (upper line) and very preterm (lower line) at day $42 ; \square=$ Luukkainen et al. [14]: at days: 1-7, 8-14, 15-21, 22-27, 28-35 (top down); $\boldsymbol{\Delta}=$ Genzel-Boroviczény et al. [15]: at days: 5, 10, 20 and 30 (top down); $\diamond=$ Rueda et al. [16]: at days: $1-5,6-15$ and $16-35$ (top down); $\mathbf{\square =}$ Kovács et al. [17]: at days: 1, 4, 7, 14 and 21 (top down).

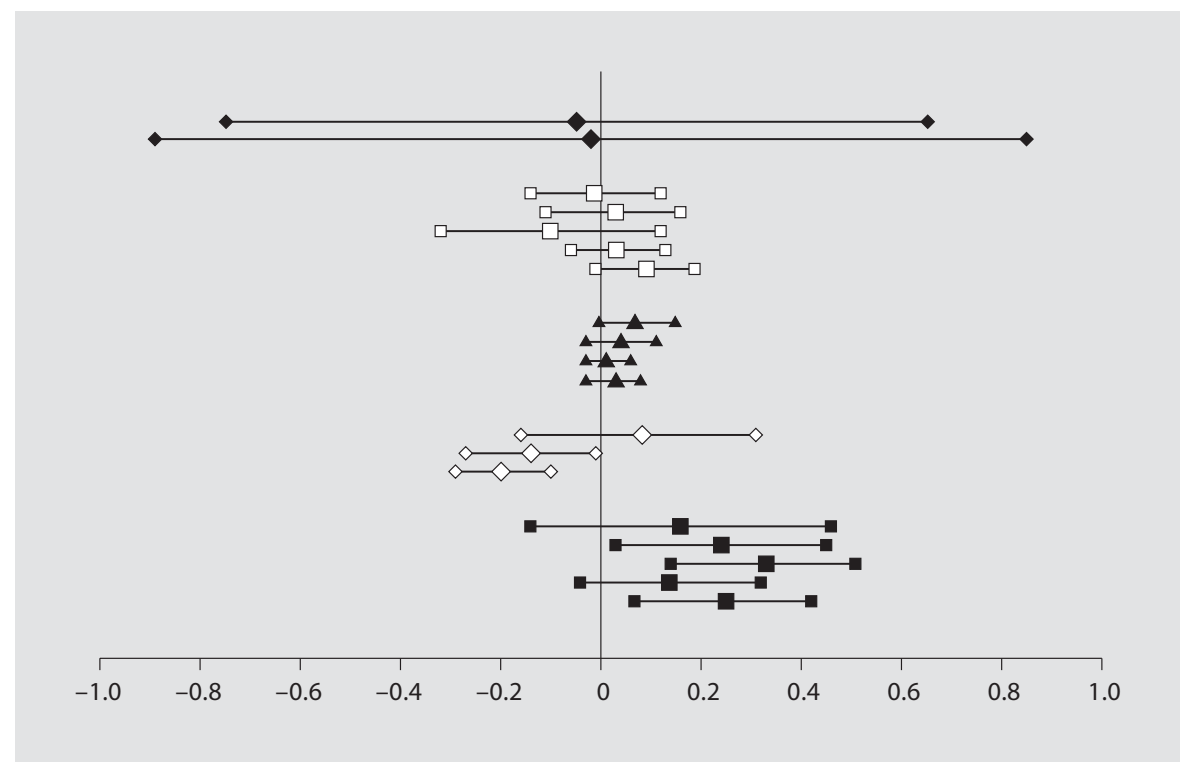

Ann Nutr Metab 2007;51:550-556 
Table 3. Major n-6 polyunsaturated fatty acids in preterm and full-term human milk

\begin{tabular}{|c|c|c|c|c|c|c|c|c|}
\hline \multirow{2}{*}{$\begin{array}{l}\text { Day of } \\
\text { lactation }\end{array}$} & \multicolumn{2}{|l|}{$C 18: 2 n-6$} & \multicolumn{2}{|l|}{ C18:3n-6 } & \multicolumn{2}{|c|}{ C20:3n-6 (DHGLA) } & \multicolumn{2}{|c|}{ C20:4n-6 (AA) } \\
\hline & preterm & full-term & preterm & full-term & preterm & full-term & preterm & full-term \\
\hline \multicolumn{9}{|c|}{ Bitman et al. [13] } \\
\hline 42 (VPT) & $15.75(4.88)$ & $15.58(4.87)$ & n.d. & n.d. & $0.51(0.52)$ & $0.53(0.51)$ & $0.55(0.72)$ & $0.6(0.71)$ \\
\hline $42(\mathrm{PT})$ & $13.83(6.63)$ & $15.58(4.87)$ & n.d. & n.d. & $0.43(0.51)$ & $0.53(0.51)$ & $0.58(0.97)$ & $0.6(0.71)$ \\
\hline \multicolumn{9}{|c|}{ Luukkainen et al. [14] } \\
\hline $1-7$ & $8.8(3.08)$ & $9.92(3.69)$ & $0.48(1.17)$ & $0.43(0.88)$ & n.d. & n.d. & $0.59(1.44)$ & $0.6(1.22)$ \\
\hline $8-14$ & $8.79(2.72)$ & $8.69(3.96)$ & $0.34(0.83)$ & $0.33(0.67)$ & n.d. & n.d. & $0.47(1.15)$ & $0.44(0.89)$ \\
\hline $15-21$ & $11.75(7.32)$ & $9.85(5.75)$ & $0.31(0.76)$ & $0.37(0.75)$ & n.d. & n.d. & $0.39(0.95)$ & $0.49(1.0)$ \\
\hline $22-27$ & $10.32(3.91)$ & $10.46(2.38)$ & $0.28(0.68)$ & $0.28(0.57)$ & n.d. & n.d. & $0.36(0.88)$ & $0.33(0.67)$ \\
\hline $28-35$ & $11.32(3.69)$ & $11.52(8.71)$ & $0.27(0.66)$ & $0.18(0.37)$ & n.d. & n.d. & $0.37(0.91)^{*}$ & $0.28(0.57)$ \\
\hline \multicolumn{9}{|c|}{ Genzel-Boroviczény et al. [15] } \\
\hline 5 & $9.86(2.17)$ & $9.81(3.26)$ & $0.31(0.64)$ & $0.11(0.08)$ & $0.59(0.29)$ & $0.55(0.23)$ & $0.72(0.12)$ & $0.76(0.14)$ \\
\hline 10 & $10.34(2.79)$ & $10.99(3.51)$ & $0.11(0.08)$ & $0.18(0.12)$ & $0.46(0.12)$ & $0.45(0.19)$ & $0.62(0.11)$ & $0.60(0.14)$ \\
\hline 20 & $9.89(2.18)$ & $11.11(4.13)$ & $0.15(0.11)$ & $0.32(0.57)$ & $0.40(0.12)$ & $0.39(0.09)$ & $0.50(0.05)$ & $0.50(0.09)$ \\
\hline 30 & $10.46(2.36)$ & $11.81(3.44)$ & $0.16(0.05)$ & $0.29(0.46)$ & $0.40(0.12)$ & $0.41(0.15)$ & $0.48(0.05)$ & $0.46(0.05)$ \\
\hline \multicolumn{9}{|c|}{ Rueda et al. [16] } \\
\hline $1-5$ & $12.59(2.7)$ & $12.42(1.83)$ & $0.14(0.06)$ & $0.22(0.2)$ & $0.73(0.15)$ & $0.69(0.25)$ & $0.91(0.29)$ & $0.83(0.3)$ \\
\hline $6-15$ & $13.07(2.75)$ & $14.22(3.66)$ & $0.18(0.04)$ & $0.09(0.04)$ & $0.55(0.07)$ & $0.62(0.2)$ & $0.71(0.12)$ & $0.85(0.17)$ \\
\hline $16-35$ & $10.75(2.03)$ & $14.3(4.02)$ & $0.18(0.03)$ & $0.06(0.01)$ & $0.4(0.04)$ & $0.47(0.09)$ & $0.46(0.04)$ & $0.66(0.14)$ \\
\hline \multicolumn{9}{|c|}{ Kovács et al. [17] } \\
\hline 1 & $14.58(3.81)$ & $16.30(2.56)$ & $0.12(0.09)^{*}$ & $0.03(0.01)$ & $0.63(0.16)$ & $0.51(0.24)$ & $0.91(0.23)^{*}$ & $0.75(0.33)$ \\
\hline 4 & $13.89(3.24)$ & $16.81(3.12)$ & $0.06(0.03)$ & $0.05(0.06)$ & $0.56(0.15)^{* *}$ & $0.34(0.12)$ & $0.76(0.22)^{*}$ & $0.52(0.19)$ \\
\hline 7 & $14.22(3.77)$ & $17.76(5.82)$ & $0.08(0.03)$ & $0.09(0.13)$ & $0.54(0.18)^{* *}$ & $0.28(0.13)$ & $0.75(0.21)^{* *}$ & $0.42(0.16)$ \\
\hline 14 & $14.72(4.50)$ & $19.49(5.15)$ & $0.08(0.03)$ & $0.05(0.04)$ & $0.46(0.15)^{*}$ & $0.27(0.08)$ & $0.57(0.20)$ & $0.43(0.16)$ \\
\hline 21 & $18.83(5.77)$ & $18.65(7.44)$ & $0.07(0.02)$ & $0.11(0.09)$ & $0.47(0.19)^{*}$ & $0.25(0.08)$ & $0.59(0.22)^{*}$ & $0.35(0.13)$ \\
\hline
\end{tabular}

$\mathrm{VPT}=$ Very preterm, $\mathrm{PT}=$ preterm; n.d. $=$ not determined.

Data are in weight percent presented as means (SD). ${ }^{*} \mathrm{p}<0.05,{ }^{* *} \mathrm{p}<0.001$.

Fig. 2. The differences of the means and the $95 \%$ CIs of the difference for docosahexaenoic acid values measured in milk samples obtained from mothers of preterm and full-term infants in five studies. For further details of the legend, see figure 1.

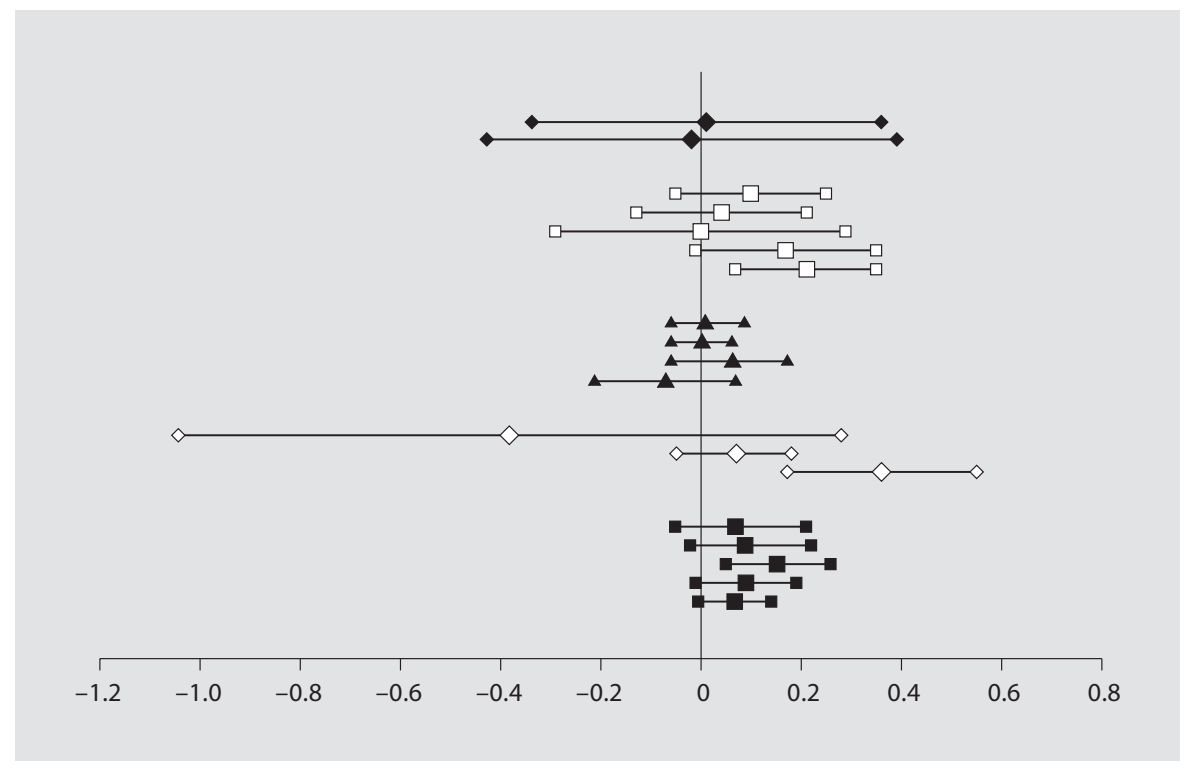




\section{Discussion}

Breast milk, which provides considerable amounts of LCPUFAs, is considered to provide the optimal form of nutrition for young infants $[8,12,18,19]$. During gestation, significant amounts of DHA and other LCPUFAs are transferred to the developing fetus for optimal growth and development by an active and selective transport $[20$, 21]. The tissue values of AA and DHA increase steadily with increasing gestational age [9]; LCPUFAs accumulate in the fetus, especially during the last trimester of pregnancy $[1,7,8]$. The availability of LCPUFAs for the development of newborn infants depends on LCPUFA stores at birth, on LCPUFA supply by way of nutrition, and on the ability of the infant to synthesize LCPUFAs from their shorter-chain precursors [22]. Due to the lack of substrate accumulation during late gestation, low-birthweight preterm infants have only very limited body stores of PUFAs and LCPUFAs at birth, whereas the requirements for deposition in their rapidly growing tissues are high $[23,24]$. The rate of synthesis may be insufficient to allow normal or optimal LCPUFA accretion in body tissues [17]. Hence, an appropriate supply of preformed dietary LCPUFAs is of crucial importance for the optimal development in infancy.

The lipid composition of breast milk can be influenced by several factors, such as the mother's diet and nutritional status during pregnancy and lactation [25], postpartum age, diurnal rhythm, differences between breasts [26], maternal diseases affecting lipid metabolism [27] as well as various other factors [11]. The question whether the fatty acid composition of human milk also depends on gestational age of the infant has been debated for many years.

In the present review, we identified three independent studies $[14,16,17]$ covering three different time points of lactation where the $95 \%$ CIs of the significant difference of mean DHA values (preterm minus full-term) were entirely in the positive range, i.e. the percentage contribution of DHA is higher in preterm than full-term milk. In contrast, data for AA were rather controversial: in the study of Kovács et al. [17] the 95\% CIs for AA values were entirely in the positive range at three different time points of lactation, whereas in the study of Rueda et al. [16] the 95\% CIs for AA values were entirely in the negative range at two different time points of lactation, i.e. both significantly higher and lower AA levels were reported in preterm compared to full-term human milk.

The LCPUFA content of human milk is closely related to maternal LCPUFA body stores [28-30]. Mothers of premature infants transfer less LCPUFAs to the fetus during a shorter pregnancy, and also the volume of human milk consumed by their infants tends to be much smaller particularly during the first weeks after birth [15], which would lead to higher maternal LCPUFA stores and thus may explain higher LCPUFA values in preterm than in full-term human milk [17]. Due to the shorter period and lesser extent of intrauterine LCPUFA accumulation, preterm infants should have higher postnatal LCPUFA requirements than full-term infants. It is tempting to speculate whether there may be other adaptive or regulative mechanism to indicate higher LCPUFA contents in preterm milk in response to higher physiological needs of preterm infants, but the occurrence of a significant survival rate of small preterm infants is a very new phenomenon relative to the time scale of human evolution and hence it appears unlikely that such mechanisms specific to preterm birth would have developed.

Nonetheless, higher DHA values in preterm than in full-term human milk indicate a likely benefit of utilizing own mother's milk for feeding preterm infants. Moreover, these data should lead to a reconsideration of the DHA levels in formulae for preterm infants, which currently tend to mimic DHA levels of full-term human milk and thus tend to differ from the fatty acid composition of human milk of mothers giving birth to preterm infants.

\section{Acknowledgments}

The studies reported herein have been carried out with partial financial support from the Commission of the European Communities, specific RTD Programme 'Quality of Life and Management of Living Resources', within the 6th Framework Programme, Contract No. FOOD-CT-2005-007036 EARNEST (Early nutrition programming project, www.metabolic-programming.org). This communication does not necessarily reflect the views of the Commission and in no way anticipates the future policy in this area. The work of the authors was partial financially supported by the Hungarian National Research Fund (OTKA 46630 to T.D.) and by the Hungarian Ministry of Health (ETT 175/2006 to T.D.).

References

Ann Nutr Metab 2007;51:550-556 555
1 Koletzko B, Rodriguez-Palermo M: Polyunsaturated fatty acids in human milk and their role in early infant development. J Mammary Gland Biol Neoplasia 1999;3: 269-284.

2 Decsi T, Koletzko B: Role of long-chain polyunsaturated fatty acids in early human neurodevelopment. Nutr Neurosci 2000;3:293306 
3 Willatts P, Forsyth JS: The role of long-chain polyunsaturated fatty acids in infant cognitive development. Prostaglandins Leukot Essent Fatty Acids 2000;63:95-100.

4 Morale SE, Hoffman DR, Castaneda YS, Wheaton DH, Burns RA, Birch EE: Duration of long-chain polyunsaturated fatty acids availability in the diet and visual acuity. Early Hum Dev 2005;81:197-203.

5 Clandinin MT, Van Aerde JE, Merkel KL, Harris CL, Springer MA, Hansen JW, Diersen-Schade DA: Growth and development of preterm infants fed infant formulas containing docosahexaenoic acid and arachidonic acid. J Pediatr 2005;146:461-468.

6 Fleith M, Clandinin MT: Dietary PUFA for preterm and term infants: review of clinical studies. Crit Rev Food Sci Nutr 2005;45:205229.

7 Aggett PJ, Haschke F, Heine W, Hernell O, Koletzko B, Launiala K, Rey J, Rubino A, Schöch G, et al: ESPGAN Committee on Nutrition: Committee report. Comment on the content and composition of lipids in infant formulas. Acta Paediatr Scand 1991;80:887896.

8 Hamosh M, Salem N Jr: Long-chain polyunsaturated fatty acids. Biol Neonate 1998;74: 106-120.

9 Clandinin MT, Chappell JE, Leong S, Heim T, Swyer PR, Chance GW: Extrauterine fatty acid accretion rates in human brain: implications for fatty acid requirements. Early Hum Dev 1980;4:130-138.

10 Clandinin MT, Chappell JE, Leong S, Heim T, Swyer PR, Chance GW: Intrauterine fatty acid accretion rates in human brain: Implications for fatty acid requirements. Early Hum Dev 1980;4:121-129.

11 Jensen RG: Lipids in human milk. Lipids 1999;34:1243-1271.
12 Hamosh M, Henderson TR, Kemper MA, et al: Long-chain polyunsaturated fatty acids (LC-PUFA) during early development: contribution of milk LC-PUFA to accretion rates varies among organs. Adv Exp Med Biol 2001;501:397-401

13 Bitman J, Wood DL, Hamosh M, Hamosh P, Metha NR: Comparison of the lipid composition of breast milk from mothers of term and preterm infants. Am J Clin Nutr 1983; 38:300-312.

14 Luukkainen P, Salo MK, Nikkai T: Changes in the fatty acid composition of preterm and term human milk from 1 week to 6 months of lactation. J Pediatr Gastroenterol Nutr 1994:18:355-360.

15 Genzel-Boroviczény O, Wahle J, Koletzko B: Fatty acid composition of human milk during the first month after term and preterm delivery. Eur J Pediatr 1997;156:142-147.

16 Rueda R, Ramírez M, García-Salmerón JL, Maldonado J, Gil A: Gestational age and origin of human milk influence total lipid and fatty acid contents. Ann Nutr Metab 1998;42 $12-22$.

17 Kovács A, Funke S, Marosvölgyi T, Burus I, Decsi T: Fatty acids in early human milk after preterm and full-term delivery. J Pediatr Gastroenterol Nutr 2005;41:454-459.

18 Jensen CL, Heird WC: Lipids with an emphasis on long-chain polyunsaturated fatty acids. Clin Perinatol 2002;29:261-281.

19 Koletzko B, Thiel I, Abiodun PO: The fatty acid composition of human milk in Europe and Africa. J Pediatr 1992;120:62-70.

20 Larqué E, Demmelmair H, Klinger M, De Jonge S, Bondy B, Koletzko B: In vivo investigation of the placental transfer of ${ }^{13} \mathrm{C}$-labeled fatty acids in humans. J Lipid Res 2003; 44:49-55.

21 Larqué E, Demmelmair H, Klinger M, De Jonge S, Bondy B, Koletzko B: Expression pattern of fatty acid transport protein-1 (FATP-1), FATP-4 and heart-fatty acid binding protein (H-FABP) Genes in human term placenta. Early Hum Dev 2006;82:697-701.
22 Innis SM: Essential fatty acids in growth and development. Prog Lipid Res 1991;30:39130.

23 Innis SM: Perinatal biochemistry and physiology of long-chain polyunsaturated fatty acids. J Pediatr 2003;143:1-8.

24 Larque E, Demmelmair H, Koletzko B: Perinatal supply and metabolism of long-chain polyunsaturated fatty acids: importance for the early development of the nervous system. Ann NY Acad Sci 2002;967:299-310.

25 Rocquelin G, Tapsoba S, Dop MC, et al: Lipid content and essential fatty acid (EFA) composition of mature Congolese breast milk are influenced by mothers' nutritional status: impact on infants' EFA supply. Eur J Clin Nutr 1998;52:164-171.

26 Jensen RG: The Lipids of Human Milk. Boca Raton, CRC Press, 1989, pp 7-23.

27 Koletzko B, Rodriguez-Palmero M: Polyunsaturated fatty acids in human milk and their role in early infant development. J Mammary Gland Biol Neoplasia 1999;4: 269-284.

28 Martin JC, Bougnoux P, Finon A, et al: Dependence of human milk essential fatty acids on adipose stores during lactation. Am J Clin Nutr 1993;58:653-659.

29 Demmelmair H, Sauerwald T, Fidler N, et al: Polyunsaturated fatty acid metabolism during lactation. World Rev Nutr Diet. Basel, Karger, 2001, vol 88, pp 184-189.

30 Del Prado M, Villalpando S, Elizando A, Rodriguez $\mathrm{M}$, Demmelmair $\mathrm{H}$, Koletzko B: Contribution of dietary and newly formed arachidonic acid to human milk lipids in women eating a low fat diet. Am J Clin Nutr 2001;74:242-247. 